\title{
The Arabic Origins of "Prepositions and Conjunctions" in English and European Languages: A Lexical Root Theory Approach
}

\author{
Zaidan Ali Jassem \\ Department of English Language and Translation, Qassim University, P.O.Box 6611 \\ Buraidah, KSA \\ E-mail: zajassems@gmail.com
}

Received: January 23, 2014 Accepted: February 4, 2014 Published: February 4, 2014

doi:10.5296/jsel.v1i1.5056 URL: http://dx.doi.org/10.5296/jsel.v1i1.5056

\begin{abstract}
This paper investigates the Arabic cognates or origins of prepositions and conjunctions in English, German, French, Latin, Greek, Russian, and Sanskrit from a lexical root theory perspective. The data consists of 104 such terms like about, at, after, among, amid, before, behind, beneath, beside, between, by, despite, in, on, to, in front of, lateral to, like, anterior to, then, than, near, next to, prior to, posterior to, toward, since, and, or, but, so, for, including, however, moreover, therefore. The results exhibit that all such words have true Arabic cognates, with the same or similar forms and meanings. However, their different forms are all found to be due to natural and plausible causes and different courses of linguistic change. For example, English $b y$ and German bei are true cognates of Arabic $b i$ 'in, with, by, for'; English to and German zu come from Arabic kai 'to, in order to' or 2atta 'to' via /2/-loss; English than (then) 'originally the' derives from Arabic dha 'this' via /n/-insertion; English though (although) descended via Old English 'theah (this)' and German doch from Arabic dha(h) 'this'; English however (how + ever) obtains from Arabic kaifa 'how', turning $/ \mathrm{k} \& \mathrm{~h} /$ into $/ \mathrm{h} \& \mathrm{w} /$. Consequently, the results indicate, contrary to Comparative Method claims, that Arabic, English, and all (Indo-) European languages belong to the same language, let alone the same family. They, therefore, prove the adequacy of the lexical root theory according to which Arabic, English, German, French, Latin, and Greek are dialects of the same language with Arabic being their origin all because of its phonetic complexity and huge lexical variety and multiplicity.
\end{abstract}

Keywords: Prepositions \& conjunctions, Arabic, English, German, French, Russian, Latin, Greek, Sanskrit, historical linguistics, lexical root theory 


\section{Introduction}

The lexical root theory (Jassem 2012a-f, 2013a-q, 2014a-b) has been so called for utilizing lexical (consonantal) roots in tracing genetic relationships between Arabic words and those of English, German, French, Latin, Greek, Sanskrit, and/or Indo-European languages. It emerged first as a rejection of the classification of the Comparative Method in historical linguistics that Arabic belongs to a different language family from English, German, French, and all (Indo-)European languages in general (Bergs and Brinton 2012; Algeo 2010; Crystal 2010: 302; Campbell 2006: 190-191; Yule 2006; Crowley 1997: 22-25, 110-111; Pyles and Algeo 1993: 61-94). On the contrary, it clearly showed the genetic relationship between Arabic and such languages phonetically, morphologically, grammatically, and semantically or lexically is too inextricably close that they can be truly considered dialects or members of the same language (Jassem 2012a-f, 2013a-q, 2014a-b).

Thus far twenty five studies have been carried out on all language levels. Phonetically, Jassem (2013c) outlined the English, German, French, Latin, and Greek cognates of Arabic back consonants: viz., the glottals /h \& \%, the pharyngeals $/ 2 \& 3 /$, the uvular /q/, and the velars $/ \mathrm{k}, \mathrm{g}, \mathrm{kh}, \& \mathrm{gh} /$. Needless to say, the phonetic analysis recurred in all the studies below. Morphologically, three studies established the Arabic origins of English, German, French, Latin, and Greek inflectional 'plural and gender' markers (Jassem 2012f), derivational morphemes (Jassem 2013a), and negative particles (Jassem 2013b). Grammatically, five papers described the Arabic origins of English, German, French, Latin, Greek, and Sanskrit personal pronouns (Jassem 2012c, 20131), determiners (Jassem 2012d), verb 'to be' forms (Jassem 2012e), and question and modal words (Jassem 2014b). Lexically, sixteen studies successfully traced the Arabic origins of English, German, French, Latin, Greek and Sanskrit words in key semantic fields- namely, numeral words (Jassem 2012a), common religious terms (Jassem 2012b), water and sea terms (Jassem 2013d), air and fire terms (Jassem 2013e), celestial and terrestrial terms (Jassem 2013f), animal terms (Jassem (2013g), body part terms (Jassem 2013h), speech and writing terms (Jassem 2013i), time words (Jassem 2013j), family words (Jassem 2013k), cutting and breaking words (Jassem 2013m), movement and action words (Jassem 2013n), perceptual and sensual words (Jassem 2013o), cognitive and mental words (Jassem 2013p), love and sexual words (Jassem 2013q), and wining and dining terms (Jassem 2014a). In all such studies, Arabic and English words, for example, were true cognates with similar or identical forms and meanings, whose different forms are due to natural and plausible causes and different courses of linguistic change. Consequently, they are dialects of the same language.

The remainder of this paper comprises four sections: (i) research methods, (ii) results, (iii) discussion, and (iv) conclusion.

\section{Research Methods}

\subsection{The Data}

The data consists of 104 prepositions and conjunctions like about, at, after, among, amid, before, behind, beneath, beside, between, by, despite, in, on, to, in front of, lateral to, like, 
anterior to, then, than, near, next to, prior to, posterior to, toward, since, and, or, but, so, for, including, however, moreover, therefore, and so on. They have been selected for their high frequency in the core vocabulary of language and everyday speech. To facilitate reference, they will be arranged alphabetically together with brief linguistic comments in (3.) below.

Regarding etymological data for English and European languages, all references are for Harper (2013) and Pyles and Algeo (1996); for Arabic data, the meanings are for Ibn Manzoor (2013) in the main and Al-Ghalayeeni (2010).

In transcribing the data, normal spelling is used for practical purposes; nevertheless, certain symbols were used for unique Arabic sounds, including $/ 2 \& 3 /$ for the voiceless and voiced pharyngeal fricatives respectively, $/ \mathrm{kh} \& \mathrm{gh} /$ for the voiceless and voiced velar fricatives each, capital letters for the emphatic counterparts of the plain consonants $/ t, d, d h, \& s /$, and /'/ for the glottal stop (Jassem 2013c).

\subsection{Data Analysis}

\subsubsection{Theoretical Framework: The Lexical Root Theory}

The analysis of the data employs the lexical root theory as a theoretical framework (Jassem 2012a-f, 2013a-q, 2014a-b). It is so called because of using the lexical (consonantal) root in examining genetic relationships between words such as the derivation of observation from serve (or simply srv). The major reason for that is because the consonantal root carries and determines the basic meaning of the word irrespective of its affixation such as observation. Historically speaking, consonantal roots have been used in classical and modern Arabic dictionaries (e.g., Ibn Manzoor 1974, 2013) for listing lexical entries, a practice first founded by Alkhaleel, an 8th century linguist, lexicographer, musician, and mathematician (Jassem 2012e).

The lexical root theory consists of a theoretical principle or hypothesis and five practical procedures of analysis. The principle states that:

Arabic and English as well as the so-called Indo-European languages are not only genetically related but also are directly descended from one language, which may be Arabic in the end. In fact, it claims in its strongest version that they are all dialects of the same language, whose differences are due to natural and plausible causes and different courses of linguistic change.

To substantiate or prove that principle empirically, five applied procedures are used in data collection and analysis, which are (i) methodological, (ii) lexicological, (iii) linguistic, (iv) relational, and (v) comparative/historical. As all have been reasonably described in the above studies (Jassem 2012a-f, 2013a-q, 2014a-b), a brief summary will suffice here.

To start with, the methodological procedure concerns data collection, selection, and statistical analysis. Apart from loan words, all language words, affixes, and phonemes are amenable to investigation, and not only the core vocabulary as is the common practice in the field (Crystal 2010; Pyles and Algeo 1993: 76-77; Crowley 1997: 88-90, 175-178). However, data selection is practically inevitable since no single study can accomplish that at one time, no matter how 
ambitious it might be. The most appropriate way for approaching that goal would be to use semantic fields such as the present and the above topics. Cumulative evidence from such findings will aid in formulating rules and laws of language change at a later stage (cf. Jassem 2012f, 2013a-f). The statistical analysis employs the percentage formula (see 2.2 below).

Secondly, the lexicological procedure is the initial step in the analysis. Words are analyzed by (i) deleting affixes (e.g., explained $\rightarrow$ plain), (ii) using primarily consonantal roots (e.g., plain $\rightarrow$ pln), and (iii) search for correspondence in meaning on the basis of word etymologies and origins as a guide (e.g., Harper 2012), to be used with discretion, though. The final outcome yields Arabic baien, baan (v) 'clear, plain; a plain' via /1/-insertion or split from $/ \mathrm{n} /($ Jassem 2013i).

Thirdly, the linguistic procedure handles the analysis of the phonetic, morphological, grammatical and semantic structures and differences between words. The phonetic analysis examines sound changes within and across categories. In particular, consonants may change their place and manner of articulation as well as voicing. At the level of place, bilabial consonants $\leftrightarrow$ labio-dental $\leftrightarrow$ dental $\leftrightarrow$ alveolar $\leftrightarrow$ palatal $\leftrightarrow$ velar $\leftrightarrow$ uvular $\leftrightarrow$ pharyngeal $\leftrightarrow$ glottal (where $\leftrightarrow$ signals change in both directions); at the level of manner, stops $\leftrightarrow$ fricatives $\leftrightarrow$ affricates $\leftrightarrow$ nasals $\leftrightarrow$ laterals $\leftrightarrow$ approximants; and at the level of voice, voiced consonants $\leftrightarrow$ voiceless.

Likewise, vowels change as well. Although the number of vowels differ greatly within and between English (Roach 2008; Celce-Mercia et al 2010) and Arabic (Jassem 2012g, 1987, 1993), all can be reduced to three basic long vowels /a: (aa), i: (ee), \& u: (oo)/ (and their short versions besides the two diphthongs /ai (ay)/ and /au (aw)/ which are a kind of /i:/ and /u:/ respectively). They may change according to modifications in (i) tongue part (e.g., front $\leftrightarrow$ centre $\leftrightarrow$ back), (ii) tongue height (e.g., high $\leftrightarrow$ mid $\leftrightarrow$ low), (iii) length (e.g., long $\leftrightarrow$ short), and (iv) lip shape (e.g., round $\leftrightarrow$ unround). In fact, the vowels can be, more or less, treated like consonants where /i:/ is a kind of $/ \mathrm{j}(\mathrm{y}) /, \mathrm{u}: / \mathrm{a}$ kind of $/ \mathrm{w} /$, and /a:/ a kind of $/ \mathrm{h} /$ or vice versa. Their functions are mainly phonetic such as linking consonants to each other in speech and grammatical such as indicating tense, word class, and number (e.g., sing, sang, sung, song; man/men). Thus their semantic weight is little, if not at all. For these reasons, vowels are marginal in significance which may be totally ignored in the analysis because the limited nature of the changes do not affect the final semantic result at all.

Sound changes lead to natural and plausible processes like assimilation, dissimilation, deletion, merger, insertion, split, syllable loss, re-syllabification, consonant cluster reduction or creation and so on. In addition, sound change may operate in a multi-directional, cyclic, and lexically-diffuse or irregular manner (for detail, see Jassem 2012a-f, 2013c).

As for the morphological and grammatical analyses, some overlap obtains. The former examines the inflectional and derivational aspects of words in general (Jassem 2012f, 2013ab); the latter handles grammatical classes, categories, and functions like determiners, pronouns, nouns, verbs, and case (Jassem 2012c-e, 20131). Since their influence on the basic meaning of the lexical root is marginal, they may also be ignored altogether. 
Regarding the semantic analysis, it examines meaning relationships between words, including lexical stability, multiplicity, convergence, divergence, shift, split, change, and variability. Stability means that word meanings have remained constant over time. Multiplicity denotes that words might have two or more meanings. Convergence means two or more formally and semantically similar Arabic words might have yielded the same cognate in English. Divergence signals that words became opposites or antonyms of one another. Shift indicates that words switched their sense within the same field. Lexical split means a word led to two different cognates. Change means a new meaning developed. Variability signals the presence of two or more variants for the same word (for detail, see Jassem 2012a-f).

Fourthly, the relational procedure accounts for the relationship between form and meaning from three angles: formal and semantic similarity (e.g., three, third, tertiary and Arabic thalath 'three' (Damascus Arabic talaat (Jassem 2012a)), formal similarity and semantic difference (e.g., ship and sheep (Jassem 2012b), and formal difference and semantic similarity (e.g., quarter, quadrant, cadre and Arabic qeeraaT '1/4' (Jassem 2012a)).

Finally, the comparative historical analysis compares every word in English in particular and German, French, Greek, and Latin in general with its Arabic counterpart phonetically, morphologically, and semantically on the basis of its history and development in English (e.g., Harper 2012; Pyles and Algeo 1993) and Arabic (e.g., Ibn Manzour 2013; Alghalyeeni 2010) besides the author's knowledge of both Arabic as a first language and English as an equal second language. Discretion should be exercised here due to uncertainties and inaccuracies, especially in Harper's work, though.

\subsubsection{Statistical Analysis}

The percentage formula is used for calculating the ratio of cognate words or shared vocabulary, which is obtained by dividing the number of cognates over the total number of investigated words multiplied by a 100. For example, suppose the total number of investigated words is 100 , of which 90 are true cognates. The percentage of cognates is calculated thus: $90 / 100=9 \times 100=90 \%$. Finally, the results are checked against Cowley's (1997: 173, 182) formula to determine whether such words belong to the same language or family (for a survey, see Jassem 2012a-b).

\section{Results}

The results will focus mainly on the Arabic lexical (consonantal) roots of English, German, French, Latin, Greek, and Sanskrit prepositions and conjunctions. Therefore, affixation (prefixes, suffixes, and infixes) will be excluded in general to save time, space, and effort here although all have true Arabic cognates (see Jassem 2012f, 2013a).

About via Old English abutan, onbutan 'on the outside of' as a compound of (i) on 'on' from Arabic $3 a n$ 'on' via /3/-loss, (ii) be 'by' from Arabic bi 'by, in, with', and (iii) utan 'outside' via Latin usque 'out' from Arabic aqSa 'far, outside' via reordering and/or /q \& $\mathrm{S} /$-merger into / $\mathrm{t} /$; alternatively, from Arabic ba3d 'after, behind, about' via lexical shift, /3/-deletion, and turning /d/ into /t/. See out. 
Above (up) via Old English abufan, onbufan as a compound of (i) on 'on', (ii) be 'by', and (iii) ufan 'over, high' and German oben from Arabic baina 'between' via lexical shift and /f \& n/-merger into /v/; or 3ubaab 'up, heights' via /3/-loss. See up.

After via Old English of + -ter 'comparative suffix' from Arabic ithra 'after' where /th/ split into /f \& t/ (cf. Greek apatero 'farther off' from Arabic ab3ad 'farther off' via /3/-loss, turning /d/ into /t/, and /r/-insertion).

Across (cross) via Old English an cros 'lit., on cross; in a crossed position' from Arabic qarfaS 'sit cross-wise' where /f \& S/ merged into /s/; a $3 \mathrm{raD}$ 'wider', $3 \operatorname{arD}$ (n) 'width', 3 aariDa(t) 'lit., a crosser; a crossed object like a log to stop entry' in which $/ 3$ \& D/ passed into /k \& s/ (see Jassem 2013n); karaz 'run and hide', karraz 'bad, vicious'; or rakkaaza(t) 'fixer, stabilizer' via reordering and turning /z/ into /s/.

Against (again) via Old English agenes, agen 'in opposition to' via/s/-genitive and /t/insertion, agan, angean (an 'on' + gean (gegen) 'against, towards') and German gegen from Arabic jana2a 'leaning towards' in which /j \& 2/ became /g \& Ø)/; or 3anna 'of something, to appear in front of you as a hurdle; head to', $3 a n$ 'about, on, from, against', 3anaan (n) 'opposition; sides', turning /3/ into /g/.

Along (long) via Old English andlang, consisting of (i) and 'opposite' from Arabic 3aneed 'against, obstinate' via /3/-loss and (ii) lang 'long, entire, continuous, all day long, alongside of' from Arabic nooq, naa'iq 'high, tall' via lexical shift and /1/-split from /n/, raaq(in) 'high, tall' via /r/-split into /1 \& n/, or salgham/samlagh 'long' via reordering, merging $/ \mathrm{s} \& \mathrm{gh} /$ into $/ \mathrm{g} /$, and replacing $/ \mathrm{m} /$ by $/ \mathrm{n} /$.

Although (though, German doch) via Old English allthough, more emphatic than though, as a compound of (i) all from Arabic al 'the' and (ii) theah 'that' from Arabic ti(h)/dhi(h) 'this (f./m.)' where /h/ became /gh/- i.e., allati/alladhi 'which, who' via lexical shift (see Jassem 2012d).

Among via Old English onmang, on gemang 'in a crowd', gemeagan (v.) 'to mingle' from Arabic jam(ee)3, ajma3(een), majmoo3 'crowd, gathering, together, all' via reordering and turning $/ 3 \& \mathrm{j} /$ into $/ \mathrm{n} \& \mathrm{~g} /$; or $m a 3 a$ 'with' via lexical shift and /3/-split into /n \& g/.

And via Old English and/ond 'thereupon, next, over there', Old High German enti, German und, Latin ante 'before, near, opposite', Greek anti (anta, anten) 'opposite, before, over against' from Arabic 3inda 'there, at' via /3/-loss; or 3ada 'except' via lexical divergence and turning $/ 3 /$ into $/ \mathrm{n} /$.

Latin and French et derives from Arabic $3 a d a$ 'except' via lexical shift, turning /d/ into $/ \mathrm{t} /$, and $/ 3 /$-loss.

Anterior to (ante, anti) via the comparative of Latin ante and Greek anta (anten, anti) 'in front of from the above Arabic 3inda 'there, at' via /3/-loss and replacing /d/ by /t/; amaam 'in front of', imaamat (n) where $/ \mathrm{m} /$ turned into $/ \mathrm{n} /$; or qiddaam 'in front of', aqdam 'fronter, older', muqaddim(at) (n) 'front' via reordering, merging /q \& d/ into /t/, and $/ \mathrm{r} /$-insertion. See and. 
Around (round) via German runde and French rond from Arabic dawr, dawaraan 'turn, going round' via reordering (cf. turn from Arabic dawaraan, turning /d/ into /t/; rotate from Arabic radada, irtadda 'go back, turn' or dawara, dawra(t)/tadweer (n) 'go round' via reversal and replacing /t/ by /d/).

As via Old English alswa 'also' and German als from Arabic ka 'like, as' (or kadhalik 'lit., like this; also') via reversal and turning /k/ into /s/; saa3(at) 'time, moment, hour, when' via reversal and merging $/ 3 \& \mathrm{~s} /$ into $/ \mathrm{s} /$; or $i d h a$ 'if, because' where $/ \mathrm{dh} /$ became $/ \mathrm{s} /$.

Furthermore, as collocates with other words, all of which have Arabic cognates:

(i) As of from Arabic $\mathrm{ka}(\mathrm{ma}) \mathrm{fee}$ 'as in' via lexical shift.

(ii) As a consequence (subsequently, sequence, sequel, second) from Latin (a) com 'with' from Arabic jamee3 'together' via /3/-mutaton into /k/ and (b) sequentia, sequi (v) 'to follow' from Arabic saaqa, sawq 'drive, follow, leg' or qassa/qaSSa 'to follow' via reordering (Jassem 2013n).

(iii) As a result via Latin resultare 'to result, rebound, spring forward', frequentative of resilire 'to rebound' from Arabic zalla, zalzal(at) 'to move' where /z/ became $/ \mathrm{s} /$; otherwise, from $2 a \operatorname{Seel}(a t)$ 'result, outcome' where $/ 2 \& \mathrm{~S} /$ merged into /s/ from which /r/ split (Jassem 2013n).

At (Latin $a d$ 'to') from Arabic 2atta 'to, in order to' via /2/-elision. Viney (2008: 19) mentioned such a usage in the Middle English poem Cursor Mundi:

\section{For the commun at understand}

'for the commoners to understand'.

back (at the back of; aback) from Arabic 3aqib 'back, behind, after' via reversal and /3/omission (Jassem 2013h).

Because via (i) Old English be- 'by' from Arabic bi 'in, with, by' and (ii) Latin causa 'cause, reason, interest, judicial process' from Arabic qiSSa(t)/qaDiya(t) 'cause, story'- i.e., biqiSSa(t) (cf. bi2aith 'so that' via lexical shift and replacing $/ 2 \&$ th/ by $/ \mathrm{k} \& \mathrm{~s} /$ ).

Before (afore, fore, pre, prior) via Old English fer 'for, before, on account of', German für, Latin per (pro, pre) 'before, for, on behalf of', porro 'for', Russian pere 'through' from Arabic fee 'in, with, to, because' via /r/-insertion; furr(at) 'head, chief; first, beginning, choicest'; baar 'first; pure, just'; or ghurra(t) 'front, first' in which /gh/ became /f/.

Behind via Old English behindan 'from behind' and German hinten from Arabic ba3d(in) 'after, behind' via reordering and turning $/ 3 /$ into $/ \mathrm{h} /$; or $2 u D n$ 'lap' via lexical shift, reordering and turning $/ 2 /$ into $/ \mathrm{h} / \mathrm{cf}$. hind (German Hinde) 'female deer' from Arabic $3 a n z(a t)$ 'female goat' via lexical shift and turning $/ 3 \& \mathrm{z} /$ into $/ \mathrm{h} \& \mathrm{~d} /$ ).

Below via Old English biloogh 'from below' from (i) bi 'by, about' and (ii) loogh (logh, low, lowe) 'low', legan (v) 'lie', lah (adj.) 'near the ground' from Arabic laqa2a 'lie/put down; tell lies' in which /q \& 2/ merged into /g (y)/, hlaw 'hill' from Arabic 3uloo 'height' in 
which /3/ became /h/, and/or hlowan 'make a noise like a cow' from Arabic khuwaar 'a cow's noise' via reordering and substituting $/ \mathrm{h} \& \mathrm{l} / \mathrm{for} / \mathrm{kh} \& \mathrm{r} /$.

Beneath via Old English beneothan 'from below', comprised of (i) be 'from' from Arabic (i) $b i$ 'in, with' and (ii) neothan 'below', nether 'underneath' (German nieder) from Arabic doon 'down, low' via reversal and turning /d/ into /th/- i.e., bidoon 'without' in Arabic via reordering.

Beside (besides) via Old English be sidan 'by the side of' from (i) be 'by' above and (ii) side, sidh (adj.) 'long part of something' and German Seite from Arabic jidaa' 'side' by turning /j/ into /s/; Saf2at 'side, a paper' via /S, f, \& 2/-merger into /s/ and turning/t/ into /d/; $2 i d h a a^{\prime}$ 'side, shoe' via $/ 2 \& \mathrm{dh} /$-mutation into $/ \mathrm{s} \& \mathrm{~d} /$; or 2 add (i.e., bi-2add(i)) 'lit., by side (my); beside (me)' where $/ 2 /$ became $/ \mathrm{s} /$.

Between via Old English betweonum, betwinum of (i) be 'by' from Arabic bi 'by, in, with' and (ii) tweon(um) 'two-(dat.)' from Arabic thaani, thawaani (pl.) 'two', turning /th/ into /t/ (Jassem 2012a); or baina 'between' via/t/-insertion as in spoken Arabic bainaat-na 'between-us'.

Beyond (yond, yon) via Old English begeondan 'beyond, from the farther side' of (i) be 'by' and (ii) geondan 'the farther side' and German jener from Arabic ghaad(in) 'farther, away, there' via reordering and turning /gh/ into /g (y)/; qiddaam 'ahead, further' via reordering and turning /q \& m/ into /g \& n/; ba3d(in) 'after, behind', ba3eed(een) 'far $(\mathrm{pl},)^{\prime}$ where $/ 3 /$ became $/ \mathrm{g}(\mathrm{y}) /$; or 3 inda 'there, at', turning $/ 3 /$ into $/ \mathrm{g} /$.

But via Old English but(a/o)n 'unless, except, without, outside' from Arabic bidoon 'without', turning /t/ into /d/; baida ('anna) 'but' in which /d/ became /t/; bas 'but, enough' in which /s/ passed into /t/; or bal 'but' where $/ 1 /$ became /s/.

By via Old English be 'near, in, by, during, about' and German bei from Arabic $b i$ 'by, in, with'. Russian $B$ /vee/ and $p a /$ bee/ come from Arabic $b i$ 'with, in' also or $f e e$ 'in'.

Concerning (concern) via Latin concernere of (i) com- 'with, together' from Arabic jamee3 'together' via /3/-loss and /j/-mutation into / $\mathrm{k} /$ (Jassem 2013a) and (ii) cernere 'to sift, mix, as in a sieve; perceive, comprehend' from Arabic qaran 'connect' via /q/-mutation into /s/ (Jassem 2013o).

Contrary to (contra, contrast, counter) via French contre and Latin contra 'against' from Arabic qanTar(at) 'bridge; any high structure' via lexical shift; 2antar 'oppose, refuse to move' via lexical shift and replacing /2/ by /k/; or qaaTi3, muqaaTi3 'lit., cutting; against' via reordering, substituting $/ \mathrm{n} /$ for $/ 3 /$, and $/ \mathrm{r} /$-insertion.

As to in contrast, it consists of Latin (i) contra above and (ii) stare 'sit' from Arabic jatha 'sit' where /j \& th/ became /s \& t/ (Jassem 2013n)

Cum (com-, con-, col-. cor-, co) via Latin 'with' from Arabic kama 'as, like' via lexical shift or $m a 3$ 'with' via reversal and turning /3/ into /k/ (Jassem 2013a). French Comme 'as, like' derives straight from Arabic kama 'as, like'. 
Despite (in spite of; despise, despicable, respect, expect) via Old French despit (depit) and Latin despectus 'looking down on', despicere (v) 'despise' from Arabic shaba2a, tashbee2(at) (n) 'see', turning /t/ into /d/ and /sh \& 2/ into /s \& t (s or k)/; or shabaha, tashbeeh(at) (n) 'see' via/sh \& h/-merger into /s (t)/ (Jassem 2013o).

Down from Arabic doon 'below, underneath, low, down'.

During (duration, endure) via Old French durer and Latin durare 'endure' from Arabic daama, dawaam (n) 'last, continue' where /m/ turned into /r/; or Tuwaal 'along, lasting, length' where $/ \mathrm{T} \& \mathrm{r} /$ became $/ \mathrm{d} \& \mathrm{r} /$.

Et cetera via Latin (i) et 'out' from Arabic 2 atta 'including, until, to' via lexical shift and /2/loss, 3ada 'except' via lexical divergence, /3/-loss, and substituting /t/ for /d/, or aiDa(n) 'also' where /D/ became /t/ and (ii) cetera 'others, more of the same' from Arabic katheer 'many, much' via $/ \mathrm{k} \&$ th/-mutation into $/ \mathrm{s} \& \mathrm{t} /$. See and.

In Spanish, $\mathbf{y}$ 'and' is used, which is cognate to Arabic wa 'and', substituting /y/ for /w/.

Except via Latin (i) ex 'out' from Arabic $a q S a$ 'out, farthest' via /q \& S/-merger into /x/ and (ii) capere 'take' from Arabic kasab or qabaD 'earn, take' via $/ \mathrm{k} \& \mathrm{~s} /$-merger into $/ \mathrm{k} /$ in the former and turning $/ \mathrm{D} /$ into $/ \mathrm{t} /$ in the latter.

Extra via the comparative of Latin ex 'out', exterus 'outside' from Arabic aqSa 'out, farthest' via /q \& S/-merger into /x/; or akthar 'more' via/th/-split into /st/.

For (fore-) via Old English fer 'for, before, on account of', German für, Latin per/pro 'before, for, on behalf of', porro 'for', Russian pere 'through' from Arabic fee 'in, with, to, because' or $f a$ 'because' via /r/-insertion. See before/per.

As to fore- 'before, previously' and for- (German ver-) 'away, opposite, a prefix indicating loss, completion, destruction, intensification', both come from Arabic faraagh 'emptiness, completion' via /r \& gh/-merger. For ever derives from Arabic dahr 'time', merging /d \& h/ into /v/. For good obtains from Arabic ghad 'day, tomorrow', turning /gh/ into/g/- i.e., fee ghad 'lit., in tomorrow'.

From via Old English fram 'from, since, by, as a result; originally forward movement, advancement', German von 'from', and Latin pro/pre 'forward, toward the front, in advance' from Arabic min 'from' where /m \& n/ became /f \& m/ besides /r/-insertion; marra, muroor (n) 'pass, advance' where $/ \mathrm{m} / \mathrm{split}$ into /f $\& \mathrm{~m} /$; baar 'first; good to' or barra(ni) 'outside' where /b/ became /f/.

However via Old English $h u$ 'how' and Latin qu- 'how' from Arabic kaifa (kai) 'how' via /k \& f/-mutation into /h \& w/ (Jassem 2014b).

\section{Hypo See sub.}

If (only if) via Old English gif (pronounced /yif/) and German ob(weil) 'if', Fench si from Arabic 'idh(a) 'if' (pronounced /iz(a)/ in spoken Syrian and Egyptian Arabic) where /dh/ became /f/. In French si, reversal and replacing /dh/ by /s/ occurred. As to German weil 
'if', it comes from Arabic law (walaw) 'if' via reordering.

As to only $(o n e+l y)$, one comes from Arabic 'awal, 'ul 'one, first' where /1/ became /n/ (Jassem 2012a). Alternatively, it comes from Arabic inna(ma) 'intensifier' or illa (in la) 'lit., not not; except' via lexical shift and /n \& 1/-merger. See like.

In via Old English in 'in, into, on, upon, at, among, about, during', inne (adv.) 'inside, within', German/Latin in, and Greek en from Arabic $3 a n$ 'about, on' via /3/-loss; $m i n$ 'from' via lexical shift and /m \& n/-merger; 'ila 'to' via lexical shift and turning /1/ into /n/; or huna 'here' via /h/-loss (cf. inn from Arabic 2aana(t) 'inn, bar' via /2/-loss (Jassem 2014a)).

Including (excluding) via Latin includere (in 'in' + claudere 'shut') 'shut in, enclose, insert, imprison' from Arabic qalad 'close, shut in; brace, spin, twist'; or dakhal 'enter' via reordering and turning $/ \mathrm{kh} /$ into $/ \mathrm{k} /$.

Inferior to (inferiority, infra) via the comparative of Latin inferus 'that is below', infra 'below, later, than, smaller than', English under, German unter, and Sanskrit adnah from Arabic adna 'lower' via /d \& n/-mutation into /f \& r/; otherwise, from Arabic naz(ee)r 'small, little', turning /z/ into /f/; naafir 'going up, bulging' via lexical shift or divergence; asfal 'lower' via /s \& 1/-mutation into /n \& r/; or naazil 'going down, low' where /z \& 1/ became /f \& $\mathrm{r} /$.

In Front of via French front 'forehead, brow' and Latin frontem, frons 'lit., that which projects; forehead, brow' from Arabic finneerat 'front, nose' via reordering or nafr(at), nafar (v) 'a projecting thing; bulge, swell, come up' via reordering.

Inter (intra, interior, internal, in, inner) via Latin inter (comparative of in) 'among, between' from Arabic $3 a n$ 'about, on' via /3/-loss or min via /m \& n/-merger and lexical shift. See in/on.

Into as a combination of in and to above; or from Arabic 3inda 'into, at; have, own' via $/ 3 /$-loss and turning $/ \mathrm{d} /$ into $/ \mathrm{t} /$.

Irrespective of (respect, inspect, expect, suspect, despise, despite) via Latin inrespectus 'looking down on', respicere (v) 'see' from Arabic shaba2a, tashbee2(at) (n) 'see' where /sh \& 2/ became /s \& s (k)/ or shabaha, tashbeeh(at) (n) 'see' via /sh \& h/-merger into /s (k)/ (Jassem 2013o). See despite.

Lateral to (unilateral, bilateral, trilateral, collateral) via Latin lateralis 'belonging to the side', lateris 'of the side', latus 'side' from Arabic lad(ee)d 'side', ladeedan (pl.) 'river sides', ladun/lada '(at the) side (of)' where /d/ became /t/; the suffix -al comes from Arabic $l i$ 'to, for' (see Jassem 2013a). (Cf. London from Arabic ladeedan (pl.) 'river sides' above via reordering and /n/-split, ladeed 'garden, park', ladin 'soft', or alandad (yalandad, anadd, aladd) 'aggressive, vicious').

Like (likely, likelihood, likewise, alike, unlike, dislike) via Old English gelic of (i) ge 'with, together' from Arabic sawa, sawia 'together' where /s/ became /g/ and (ii) lik 'body, form' from Arabic shakl 'form, shape' via reversal and /sh \& k/-merger or kull 'all, total; 
like, as' via reversal.

As a verb, it came from Old English lician 'to please, be sufficient' from lik 'body, form, like, same' from Arabic laaqa 'to be suitable and nice; to like' or lahaq 'to like dearly' $\mathrm{via} / \mathrm{h} \& \mathrm{q} /$-merger into $/ \mathrm{k} /$.

Meso- (Mesopotamia, mesolect) from Arabic masaa' 'of the road, middle'. See mid.

Mid (amid, amidst, in the midst of) from Arabic mata 'mid, middle, in, when' (cf. mediate from Arabic matta 'connect, relate to'; method from Arabic maatta(t), mawaat (pl.) 'means, method', turning $/ \mathrm{t} \& \mathrm{t} /$ into /th $\& \mathrm{~d} /$ ).

Moreover via Old English mara 'greater, stronger, mightier, more' (comparative of micel 'great') and German mehr 'more' from Arabic jamal, jumla(t), jameel 'camel, amount, big, great, beautiful' via reordering and turning $/ \mathrm{j} /$ into $/ \mathrm{s} /$; or murr 'powerful, strong, bitter', marra(t) 'much, strong, a time'. See over.

Near (nearly, next, nigh) via the comparative of Old English neah/neh 'nigh, near, from below' and German nach 'towards' from Arabic na2wa 'toward, near' (spoken naa2 in Damascus Arabic), turning $/ 2 /$ into $/ \mathrm{h} /$.

Next to (near, nigh) via the superlative form niehsta (nehsta, nyhsta) 'next' of Old English neah/neh 'nigh, near, from below' above and German nächst (nach) 'towards, below' from Arabic na2wa 'toward, near', turning /2/ into /h/.

In German, nach co-occurs with von as in:

a) Von MTV nach Mecca (a book by German TV journalist Christina) from Arabic (a) min 'from' where $/ \mathrm{m} /$ became /v (f)/ and (b) na2wa (naa2 in Damascus Arabic) 'towards', replacing $/ 2 /$ by $/ \mathrm{kh}$ (ch)/. In addition, von 'son of' (e.g., Zaidan von Jassem) comes from Arabic bin 'son', turning /b/ into /v/.

b) Die Reise von Damascus nach Berlin 'The trip from ...to...' where die 'the' comes from Arabic dha 'this' in which /dh/ turned into /d/ (Jassem 2012d); Reise 'trip, journey' from Arabic sayr(aan) 'walk, trip' via reversal or rawaa2 'leaving' where $/ 2 /$ became $/ \mathrm{s} /$. That's Arabic 100\%.

Similarly, von collocates with bis as in Von 8 bis $10 \mathrm{Uhr}$ 'from 8 to 10 o'clock' where bis consists of (i) $b(e) i$ - 'by, at, to' from Arabic bi 'by, in, with' and (ii) zu 'to' from Arabic 2atta 'to' via /2/-loss; or bas 'finished'. See by \& to. Otherwise, from Arabic Sawb 'towards' via reversal.

Notwithstanding as a compound of (i) not from Arabic $m i D$ 'not' where $/ \mathrm{m} \& \mathrm{D} /$ became $/ \mathrm{n}$ \& t/ (cf. Jassem 2013b), (ii) with from Arabic below, and (iii) stand via Latin stare 'sit' from Arabic jatha 'sit' where /j/ became /s \& t/ (Jassem 2013n).

Nonetheless as a compound of (i) none from Arabic in 'not' via /n/-split (Jassem 2013b), (ii) the from Arabic dha 'this' (Jassem 2012d), and (iii) less from Arabic laisa 'not' (Jassem 2013b); alternatively, from Arabic ma3adhalik 'lit., with that; however' via/3/-loss and 
turning $/ \mathrm{m} \& \mathrm{k} /$ into $/ \mathrm{n} \& \mathrm{~s} /$.

Of 'possessive as in the lady of the house' from Arabic dhu (dha, dhi) 'whose, of; this' via reversal and turning / $\mathrm{dh} /$ into $/ \mathrm{f} /$. See if.

The same applies to French du/de 'of' where /dh/ became /d/. Similarly, Italian della consists of (i) de 'of' as in French and (ii) la 'the' from Arabic al- 'the' via reversal, which, as a whole, is a mirror-image of Arabic alladhi 'who' (Jassem 2013d).

Off 'emphatic of in Old English' indicates stoppage and termination and occurs usually with phrasal verbs such as cut off, turn off and in swear words such as pi-- off, fu-- off, -od off. It might be derived from Arabic fee 'in' via lexical shift, waffa 'completed', waqqaf 'stop', or 3aaf/3awf 'leave, give up' via /3/-loss (cf. cut from Arabic qaTTa 'cut' and cut off from Arabic qaTTaf 'pick up, cut' (Jassem 2013m).

On via Old English an/on 'in, on, into', German an, Greek ana, Latin an- from Arabic 3an 'on, about' via /3/-loss. See in.

In German, um is used before time points or days of the week as in Er kommt um acht Uhr am Sonntag 'He comes at 8 o'clock on Sunday'. Its Arabic cognate might be yawm (yom) '(on the) day (of)' via reduction or 2een 'time, when' in which $/ 2 /$ was deleted and $/ \mathrm{n} /$ became $/ \mathrm{m} /$.

Opposite to (opposition, opponent, position, post) via Latin oppositus 'standing against, opposite', opponere (v) (ob 'against' + ponere 'place' from Arabic bain 'mid land, between'; basaT 'place, spread'; 2aabisa(t) 'stopping' via/2/-loss; bazz(at) 'to overcome, steal, imprison; a pose, dress'; or $\operatorname{Sawb}(a t)$ 'towards, around, aim, declension' via reversal and lexical shift.

Or (French ou) via Old English oththe 'either, or' via /r/-insetion, German oder, Old Norse etha from Arabic 'au dha 'or this', ya dha ya dha, 'either this or this' via merger; 'au 'or' via/r/-insertion; or ghair 'different, other, or' in which /gh/ merged into /r/.

Or else via Old English elles 'other, different', Greek allos 'other', Latin alius (alias) from 'Arabic alladhi 'who' (al 'the' + dhi 'this, whose') or alshai' 'the thing' via lexical shift and replacing /dh (sh)/ by /s/.

Other than via Old English other 'the second' and German andar from Arabic thaan(i) 'second, next, other' via reordering and turning /n/ into /r/ (Jassem 2012a). See than/then.

Otherwise via Old English on other wisan 'in the other manner' from (i) on \& other above and (ii) wis, German Weise 'way, manner' from Arabic wajh, wijha(t) (pronounced wish in Damascus Arabic (Jassem 1987, 1993, 1994) 'face, side, aspect, road' via /j \& h/merger into $/ \mathrm{s} /$.

Out (outside of) via Old English $u t$ 'out, outside' and German aus, Latin usque 'all the way to' from Arabic qaaSi, aqSa 'out, far' via /q \& S/-merger into/t/; 'ata, 'aat (adj.) 'come' via lexical shift or divergence; or faat 'enter, passed' via lexical shift or divergence and /f \& 
t/-merger.

Over (overseas, overeat) via Old English ofer 'beyond, above, in, upon, across, past, on high', German über from Arabic waraa' 'beyond' where /w/ became /v/; 3ala 'on', 3aal(ee) (adj.) 'high' via reordering and replacing $/ 3 \& 1 /$ by /v \& r/; $3 a b r(a)$ 'across' via $/ 3 \&$ b/merger into $/ \mathrm{v} /$; or fawq 'above' via reordering and turning $/ \mathrm{q} /$ into $/ \mathrm{r} /$..

Par (excellence) via Latin per (excellentiam) 'by the way of (excellence)' from Arabic bi 'in, by' via /r/-insertion. See per.

\section{Past See post.}

Per via Latin per 'through, during, by means of, as in; forward, before, early, first, chief, toward, against, near, at, around' and Greek peri/paros 'around, beyond' from Arabic bi via /r/-insertion or barra 'outside'. See prior.

Post (posterior to, past) via Latin post 'after, behind' from Arabic ba3d(a) 'after' (and/or ba3ath 'send') in which /3 \& d (th)/ developed into /s \& t/ (see Jassem 2013f).

Prior to (priority, prioritize, prioritization, a priori; pre) via Latin prior/per 'former, first, previous' from Arabic qabl(a) 'before, in front of', qabliat (n) via reordering and the merger of /q \& 1/ into /r/; or baar 'the first (of every month)'.

Rear (at the rear of; arrears, arrear; Latin retro 'back, behind') from Arabic waraa' 'behind, rear' via /r/-split and /' \& w/-merger into /a/ (cf. rear 'take care, graze' from Arabic ra3a, ra3ra 3 'take care, graze' via $/ 3 /-$ loss.)

Regardless of (regard, guard, guardian, warden) via French regarder 'look' (re 'again', garder 'look', + less 'not') from Arabic (i) ghaDDa 'to look away' via /gh \& D/-mutation into $/ \mathrm{g} \& \mathrm{~d} /$ and /r/-insertion (Jassem 2013o) and (ii) laisa 'not' (Jassem 2013b). See toward.

Relative to (relate, relation, relativity) from Arabic walad 'child, to be born' via lexical shift, reordering, turning /d/ into /t/, and /r/-split from /1/; or ladda/latta 'relate to' (Jassem 2013k).

Save (save for; safe, saviour, salvation, salvage) via Latin salvare 'make safe, secure', salvus 'safe' from Arabic siwa 'save for, except', sawee 'equal, safe, whole' where /w/ became /v/; or 2aasha 'save for, keep away from' via reversal and passing /2/ into /v/.

As a verb in save it 'keep, put aside, secure', it derives from Arabic Safa/Saffa 'to be safe, pure; remain'; 2awwash 'save, bring' or 2afiDha 'keep, save' in which /2/ became /s/ while /f \& Dh/ merged into /s/.

Semi from Arabic zaam 'quarter' via lexical shift and turning /z/ into /s/ or niSf (niS in spoken Arabic) 'half' via reversal and turning $/ \mathrm{S} \& \mathrm{n} /$ into $/ \mathrm{s} \& \mathrm{~m} /$ (cf. sum from Arabic zuwaim, zaama(t) 'group, gathering' via/z/-mutation into /s/ or jam3 'gathering' via/3/loss and turning $/ \mathrm{j} /$ into $/ \mathrm{s} /$ ). 
Since via Old English sithen, siththan 'originally sidh dhan 'after that (/n/ = dat. suff.), afterward, later, from now on' from Arabic (i) mudh/mundhu 'since, after' via $/ \mathrm{m} /-$ mutation into /s/ and (ii) $d$ ha 'this' via /n/-insertion; thumma 'after that' via/th/-split into $/ \mathrm{s}($ th)/ and turning $/ \mathrm{m} /$ into $/ \mathrm{n} /$; or sana(t) 'lit., year; since' via reordering and turning $/ \mathrm{t} /$ into $/ \mathrm{s}($ th) $/$.

So via Old English swa 'in this way, so as, very, consequently, therefore, either', German so, Latin suad 'so', Greek hos 'as' from Arabic ka-dha 'like this; this way, thus, so' in which $/ \mathrm{k} \& \mathrm{dh} /$ merged into $/ \mathrm{s} /$; dha 'this' where $/ \mathrm{dh} /$ turned into $/ \mathrm{s} /$; or $f a$ - 'so; a resumptive particle' in which /f/ became /s/.

So collocates with just so, which, as a whole, might derive from Arabic faqaT dha 'only this' via reordering, turning /f, q, \& $\mathrm{T} /$ into /s, j, \& t/ (cf. qiST 'just, fair' where /q/ turned into / $\mathrm{j} /$; saa3at 'lit., hour' (spoken issat (issa3at) 'this hour, now' in Damascus Arabic or hassa3 'this hour, right now' in my accent (Jassem 1987, 1993)) via /3/-loss or merger with $/ \mathrm{s} /$ and /y/-mutation into $/ \mathrm{j} /$ ).

Sub via Latin sub $(u b)$ 'under, at the foot of; close, up to, toward, within, during' and Greek hypo 'under' from Arabic ka3b 'lit', ankle; bottom, below' via /k \& 3/-merger into /s/; $3 u b b$ 'breast, within, inside, under', turning /3/ into /s (h)/; shi3b 'branch, gap, sub' via lexical shift and /sh \& 3/-merger into /s/; or Sawb 'going down', turning /S/ into /s/.

Superior to (super, supra, superiority; hyper) via Latin super 'above, over, beyond' and Greek hyper from Arabic Subar 'highest' or kabeer 'big' via lexical shift and turning /k/ into $/ \mathrm{s} /$.

Surreal (survival, surname) via French sur (sour, sor) 'over, above, beyond, in addition' from Latin super from Arabic above or from Arabic Dhahr 'back, top, above', merging /Dh \& $\mathrm{h} /$ into $/ \mathrm{s} /$.

Than (then) via the Old English demonstrative pronoun tha/to 'this', Sanskrit ta, Old Church Slavonic to, and Greek to from Arabic dha/ti(h) 'this' via /n/-insertion. Latin talis comes form Arabic tilk'that' where $/ \mathrm{k} /$ became $/ \mathrm{s} /$.

Then (than; dann in German) from Arabic as in than above; otherwise, from Arabic thumma 'then' where $/ \mathrm{m} /$ became $/ \mathrm{n} /$ or 'ithin 'time, then'.

Therefore via Old English (i) thoer 'in, at that place' and German da (dar earlier) from Arabic dha 'this' and (ii) fore above.

Though (athough) via Old English theah 'that', German doch, Latin/Greek ta 'that', and Sanskrit tah 'that' from Arabic $t i(h) / d h i(h)$ 'this (f./m.)' via /g/-insertion or /h/-mutation (see Jassem 2012d). See although.

Through via Old English thurh with over 500 spellings in Middle English (Viney 2008: 25), German durch, Latin trans from Arabic thughr(at) 'hole, gap, through' via reordering; daarij or Taariq 'going, passing', turning /d (T) \& j (q)/ into /th \& h (gh)/. 
Thus via Old English thus 'that', related to that, from Arabic dhi(h) 'this', turning /h/ into /s/ (see Jassem 2012d).

Till (until) via Old Norse/English til 'to, until' and German Ziel 'end, goal' from Arabic Teel(at), Tuwaal 'all along' via reordering and turning /T/ into/t/; or Arabic Daalla(t) 'end, goal, something stray/found'. See until.

As a verb, till 'cultivate' comes from Arabic fala2 'till, plow' via/f/-mutation into /t/ and /2/-loss.

To via Old English to 'in the direction of, further', German $z u$, Latin and French de, and Greek suffix -de from Arabic 2atta 'to, until' via/2/-deletion; kai 'to, in order to' in which /k/ became /t/; $l i$ 'to' where /1/ became /t/; or fee 'with, by, in, because' in which /f/ became $/ \mathrm{t} /$.

As a prefix in tonight 'this night', it comes from Arabic $t i(h)$ 'this'.

Toward (ward) via Old English toweard 'in the direction of; coming, approaching' (to + weard) from Arabic waarid 'coming, approaching'. (Cf. ward from Old English weard 'a guardian, watchman', weardian (v) 'to take care', German Wart, French garder from Arabic daar (baalahu) 'to take care of, watch' via reordering.)

Under via Old English under 'under, among', Latin infra, and Sanskrit adnah 'under' from Arabic 'adna 'lower', comparative of doon 'below, down' above via reordering and /r/insertion; or 'in2adar 'to go down' via /2/-loss. See infra.

Unless via Old English onlesse (on lesse than) 'on a less condition (than)' from Arabic (i) 3an 'on' via /3/-loss or in 'not' and (ii) laisa 'not' or qaleel, aqal 'little' via reordering and turning /q/ into /s/ (Jassem 2013b). See on.

Unlike (like, alike, dislike, likely) from Arabic (i) in 'not' (Jassem 2013b) and (ii) shakl 'form, shape' or via reversal and merging /sh \& k/. See like.

Until via Old English until 'until, up to' as a compound of (i) Old Norse und 'up to', Old English ende 'end, limit, boundary, conclusion' from Arabic nihayat, intaha (v) 'end' via $/ \mathrm{h} /$-loss and replacing /t/ by /d/ and (ii) till above.

Up (upper, upward) via Old English up, uppe and German auf from Arabic bi 'in, by, with' or fee 'in' via lexical shift (cf. What's up? (Jassem 2014b); 3ubb, 3ubaab (pl.) 'top, first' via /3/-elision; or iyab 'coming back' via lexical shift.

Versus (reverse, revert, averse, inverse, diverse, divert, diverge, coverge) via Latin versus 'turned around, against', vertare/versare 'to turn, wind', German werden from Arabic fara $(q / j)$ 'diverge, turn aside' via lexical shift and replacing /q (j)/ by /s/; fatal 'turn' via reordering and turning /1/ into /r/; or raja 3 'turn back' via reordering and turning $/ 3 \& \mathrm{j} /$ into /v \& s/ (Jassem 2013n).

Via (deviate, deviation, deviance) from Latin via 'way, road, channel, course' from Arabic wafy 'upland, high ground' via /w \& f/-merger; fuwaha(t) 'start of the road', tafawwaha 
(v) 'separate', merging /f, w, \& h/ into /v/; or fee 'in, through, by, because' (cf. faa'a (v) 'return' via lexical shift).

Vis-à-vis via French vis-à-vis 'face to face', visage 'face', Latin visus 'a look, vision', videre (v) from Arabic wajh(an li) wajh 'face to face' via /w/-mutation into /v/ and /j \& h/merger into /s/ (cf. Jassem 2013h, 2013o); or 'izaa' 'versus' where /'/ became /v/.

Whether (or no) via Old English hwedher 'if' and German weder from Arabic 'idha 'if' (pronounced withe in my accent (Jassem 1987, 1993, 1994)) via /'/-mutation into /w/ and $/ \mathrm{r} /$-insertion. See if.

With via Old English with 'against, toward, opposite' and German mit 'with' from Arabic ma3a/ma3ia(t) 'with' via lexical divergence, /3/-loss, and turning /t/ into /th/.

French avec 'with' derives from Arabic ma3a 'with', turning /m \& 3/ into /v \& k/. Similarly, Greek mazi 'with' is derived from Arabic ma3a 'with', replacing /3/ by /z/.

Within via Old English withinan 'against the inside'. See with \& in.

Yet via Old English get, gieto 'till now, thus far, earlier, at last, also' (e.g., I have not seen him yet) and Old High German ieuzo from Arabic qaTT 'not yet, never', turning /q/ into /g (y)/; or 2atta 'until' where /2/ became /g (y)/.

Zurück 'back in German' from Arabic rujoo3, taraaju3 'back, return' via /t \& j/-mutation into /z \& k/ and /3/-loss.

To sum, the total number of prepositions and conjunctions amounted to 104 in English, all of which had true Arabic cognates: i.e., 100\%. The same situation applies to all other IndoEuropean languages.

\section{Discussion}

The above results clearly demonstrate that prepositions and conjunctions in Arabic, English, German, French, Russian, Latin, Greek, and Sanskrit are true cognates owing to their similar or identical forms and meanings. However, their differences are due to natural and plausible causes and different courses of change phonetically, morphologically, and semantically. As all the prepositions and conjunctions have true Arabic cognates, where the percentage of shared vocabulary between Arabic, English, German, French and so on amounted to $100 \%$ in this study, this indicates that they are members or dialects of the same language according to Cowley's (1997: 172-173) classification which sets an 80\% ratio for such membership. Indeed, such languages are distant Arabic dialects in reality.

Thus the results agree with all the findings of previous studies (Jassem 2012a-f, 2013a-q, 2014a-b) in which English, German, French, Latin, Greek, Sanskrit and Arabic were all found to be rather dialects of the same language, let alone the same family. Moreover, they lend further support to the lexical root theory which has been found as adequate for the present 
study as it was for the previous ones. The main principle which states that Arabic, English, German, French, Latin, Greek, and Sanskrit, and so on are not only genetically related but also are dialects of the same language is, therefore, theoretically sound, verifiably accurate, and empirically true. Retracing English prepositions and conjunctions to true Arabic cognates is the clearest such proof on all levels of phonetic, morphological, grammatical, and semantic analysis (see below).

Semantically speaking, all the words were related to one another in various ways. Lexical stability was the general pattern where words maintained their basic meanings across the languages. The recurrence of lexical convergence in the data was due to formal and semantic similarity between Arabic words, on the one hand, and their English cognates, on the other. For example, to/zu may be derived from either Arabic (i) $k a i$ 'to, in ordr to' via $/ \mathrm{k} /$-mutation into /t (z)/ or (iii) 2atta 'to, until' via /2/-loss; all are formally and semantically similar. Beside is another example. Likewise, semantic multiplicity was common, where some English words had more than one meaning, which might have more than one likely Arabic cognate; for instance, unless and until may function as prepositions and as separate words, which all derive from formally and semantically similar Arabic words; for example, less comes from (i) Arabic qal(eel) 'little' via reversal and turning /q/ into /s/ and/or (ii) laisa 'not'. Lexical split was plentiful such as than, then, thus, (the), though, to, so, therefore, all of which developed from Old English tha 'this' which in turn came from Arabic tha(h)/ti(h) 'this'. Lexical shift was also rife as in Arabic dha 'this' (alladhi 'who') above, which shifted from being a demonstrative pronoun to a concessive conjunction in English and German although/doch. Lexical variability shows in the different forms for words like by (be-, bi) in English, for instance, bei (bi-) in German, on/an in English, Latin, Greek, and French.

What do such findings signify? The answer to this has already been detailed in Jassem (2014a-b). Briefly, they signify that Arabic, English, German, French, and so on are dialects of the same language for having the same words with similar or identical forms and meanings (cognates), with Arabic being the source or parent language because of its phonetic complexity and lexical multiplicity and variety. They, therefore, imply that the so-called proto-Indo-European language hypothesis is fictitious work which should, subsequently, be rejected outright because all English, German, and French words, for instance, are traceable to Arabic sources. Finally, they show, as a result, that there is no need to reconstruct an old world language; rather that old language has survived into today's languages here, the closest descendant of which is Arabic.

\section{Conclusion and Recommendations}

To summarize, the main results of the study were as follows:

i) The 104 prepositions and conjunctions in English, German, French, Russian, Latin, Greek, Sanskrit, and Arabic are true cognates with the same or similar forms and meanings. However, their differences are due to natural and plausible causes and courses of phonetic, morphological, and lexical change (cf. Jassem 2012a-f, 2013a-q, 2014a-b). 
ii) Phonetically, the main changes included substitution, reversal, reordering, split, and merger; lexically, the recurrent patterns were stability, convergence, multiplicity, shift, split, change, and variability; the abundance of convergence and multiplicity arise from the formal and semantic similarities between Arabic words from which English and European words stemmed in the first place.

iii) The phonetic complexity, huge lexical variety and multiplicity of Arabic prepositions and conjunctions compared to those in English and European languages point to their Arabic origin in essence.

iv) The lexical root theory has been adequate for the analysis of the close genetic relationships between prepositions and conjunctions in Arabic, English, German, French, Latin, Greek, and Sanskrit according to which they are all dialects of the same language with Arabic being the parent language.

v) Finally, the current work supports Jassem's (2012a-f, 2013a-q, 2014a-b) calls for further research into all language levels, especially lexis or vocabulary. The application of such findings, moreover, to language teaching, lexicology and lexicography, translation, cultural (including anthropological and historical) awareness, understanding, and heritage is badly needed to promote and disseminate cultural understanding and cooperation for differences are meant to understand and enrich, not divide and clash. So this is a very good opportunity for cross-cultural investment with high dividends, indeed.

\section{Acknowledgements}

I wish to warmly thank everyone who contributed to this research in any way worldwide. For my supportive and inspiring wife, Amandy M. Ibrahim, I remain indebted as ever.

\section{References}

Algeo, J. (2010). The origins and development of the English language. (6th edn.). Wadsworth Cengage Learning.

Al-Ghalayeeni, A. M. (2010). Jaami3 Al-duroos Al-3arabiyat. Saida and Beirut: Al-Maktabat Al-3aSriyat.

Bergs, Alexander and Brinton, Laurel (eds). (2012). Handbook of English historical linguistics. Berlin: Walter de Gruyter.

Campbell, L. (2006). Historical linguistics: An introduction. (2nd edn). Cambridge, Mass.: The MIT Press.

Celce-Murcia, M. et al. (2010). Teaching pronunciation: A course book and reference guide. (2nd edn). Cambridge: Cambridge University Press. 
Crowley, T. (1997). An Introduction to historical linguistics. (3rd edn). Oxford: Oxford University Press.

Crystal, D. (2010). The Cambridge encyclopedia of language. (3rd ed). Cambridge: Cambridge University Press.

Harper, Douglas. (2013). Online etymology dictionary. Retrieved http://www.etymonline.com (January 12, 2014).

Ibn Manzoor, Abi Alfadl Almisri. (2013). Lisan al3arab. Beirut: Dar Sadir. Retrieved http://www.lisan.com (January 11, 2014).

Jassem, Zaidan Ali. (1987). Phonological variation and change in immigrant speech: A sociolinguistic study of a 1967 Arab-Israeli war immigrant speech community in Damascus, Syria. PhD Thesis, Durham University, UK. Retrieved http://etheses.dur.ac.uk/1682/1/1682.pdf (January 11, 2014).

(1993). Dirasa fi 3ilmi allugha al-ijtima3i: Bahth lughawi Sauti ijtima3i fi allahajat al3arabia alshamia muqaranatan ma3a alingleeziyya wa ghairiha. Kuala Lumpur: Pustaka Antara. Retrieved http://www.academia.edu (January 11, 2014).

(1994a). Impact of the Arab-Israeli wars on language and social change in the Arab world: The case of Syrian Arabic. Kuala Lumpur: Pustaka Antara.

. (1994b). Lectures in English and Arabic sociolinguistics, 2 Vols. Kuala Lumpur: Pustaka Antara.

. (2012a). The Arabic origins of numeral words in English and European languages.

International Journal of Linguistics 4 (3), 225-41. URL: http://dx.doi.org/10.5296/ijl.v4i3.1276

. (2012b). The Arabic origins of common religious terms in English: A lexical root theory approach. International Journal of Applied Linguistics and English Literature 1 (6), 59-71. URL: http://dx.doi.org/10.7575/ijalel.v.1n.6p.59

. (2012c). The Arabic origins of English pronouns: A lexical root theory approach.

International Journal of Linguistics 4 (4), 83-103. URL: http://dx.doi.org/10.5296/ijl.v4i4.227.

. (2012d). The Arabic origins of determiners in English and European languages: A lexical root theory approach. Language in India 12 (11), 323-359. URL: http://www.languageinindia.com.

. (2012e). The Arabic Origins of Verb "To Be" in English, German, and French: A Lexical Root Theory Approach. International Journal of Applied Linguistics and English Literature 1 (7), 185-196. URL: http://dx.doi.org/10.7575/ijalel.v.1n.7p.185.

. (2012f). The Arabic origins of number and gender markers in English, German, French, and Latin: a lexical root theory approach. Language in India 12 (12), 89-119. URL: http://www.languageinindia.com. 
. (2013a). The Arabic origins of derivational morphemes in English, German, and French: A lexical root theory approach. Language in India 13 (1), 48-72. URL: http://www.languageinindia.com.

. (2013b). The Arabic origins of negative particles in English, German, and French: A lexical root theory approach. Language in India 13 (1), 234-48. URL: http://www.languageinindia.com.

. (2013c). The English, German, and French cognates of Arabic back consonants: A lexical root theory approach. International Journal of English and Education 2 (2): 108-128. URL: http://www.ijee.org.

. (2013d). The Arabic origins of "water and sea" terms in English, German, and French: A lexical root theory approach. Language in India 13 (2): 126-151. URL: http://www.languageinindia.com.

. (2013e). The Arabic origins of "air and fire" terms in English, German, and French: A lexical root theory approach. Language in India 13 (3): 631-651. URL: http://www.languageinindia.com.

. (2013f). The Arabic origins of "celestial and terrestrial" terms in English, German, and French: A lexical root theory approach. International Journal of English and Education 2 (2): 323-345. URL: http://www.ijee.org.

. (2013g). The Arabic origins of "animal" terms in English and European languages: A lexical root theory approach. Language in India 13 (4): 68-106. URL: http://www.languageinindia.com.

. (2013h). The Arabic origins of "body part" terms in English and European languages: A lexical root theory approach. International Journal of Current Applied Linguistics and English Literature (1). URL: http://www.bretj.com

. (2013i). The Arabic origins of "speech and writing" terms in English and European languages: A lexical root theory approach. Language in India 13 (5): 108-159. URL: http://www.languageinindia.com.

. (2013j). The Arabic origins of "time words" in English and European languages: A lexical root theory approach. Language in India 13 (6): 274-97. URL: http://www.languageinindia.com.

. (2013k). The Arabic origins of "family words" in English and European languages: A lexical root theory approach. International Journal of English and Education 2 (3): 261-77. URL: http://www.ijee.org.

. (20131). The Arabic origins of "personal pronouns words" in English, German, and French: A lexical root theory approach (In Arabic). 8th International Conference of Arabic Speech Renewal, Imam Bonjul University, Indonesia, 28-31 August 2013. URL: http://www.ijee.org. 
. (2013m). The Arabic origins of "cutting and breaking words" in English and European languages: A lexical root theory approach. Research Journal of English Language and Literature 1 (2): 155-68. URL: http://rjelal.com.

. (2013n). The Arabic origins of "movement and action words" in English and European languages: A lexical root theory approach. Research Journal of English Language and Literature 1 (3): 187-202. URL: http://rjelal.com.

. (2013o). The Arabic origins of "perceptual and sensual words" in English and European languages: A lexical root theory approach. Research Journal of English Language and Literature 1 (4): 212-24. URL: http://rjelal.com.

. (2013p). The Arabic origins of "cognitive and mental words" in English and European languages: A lexical root theory approach. International Journal of English and Education 2 (4): 65-83. URL: http://www.ijee.org.

. (2013q). The Arabic origins of "love and sexual words" in English and European languages: A lexical root theory approach. International Journal of Language and Linguistics 1 (4): 97-114. http://dx.doi.org//10.11648/j.ij11.20130104.13

. (2014a). The Arabic origins of "wining and dining words" in English and European languages: A lexical root theory approach. International Journal of English and Education 1 (4): 146-74. URL: http://www.ijee.org.

. (2014b). The Arabic origins of "question and auxiliary words" in English and European languages: A lexical root theory approach. International Journal of Language and Linguistics 2 (1). URL: http://www.ijll.org.

Pyles, T. and J. Algeo. (1993). The origins and development of the English language. (4th edn). San Diego: HBJ.

Roach, P. (2008). English phonetics and phonology: A practical course. (4th edn). Cambridge: Cambridge University Press.

Ruhlen, M. (1987). A guide to the world's languages: Classification, vol 1. London: Arnold. . (1994). On the origin of languages: Studies in linguistic taxonomy. Stanford, Ca.: Stanford University Press.

Viney, B. (2008). The history of the English language. Oxford: Oxford University Press. Yule, G. (2006). The study of language. (3rd ed). Cambridge: Cambridge University Press.

\section{Copyright Disclaimer}

Copyright reserved by the author(s).

This article is an open-access article distributed under the terms and conditions of the Creative Commons Attribution license (http://creativecommons.org/licenses/by/3.0/). 